\title{
Influence of organosilicon admixtures on the hydration of Portland cement
}

\author{
Kalina Grabowska ${ }^{1}$ (1) $\cdot$ Marcin Koniorczyk ${ }^{1}$ (i)
}

Received: 24 August 2020 / Accepted: 29 June 2021 / Published online: 17 July 2021

(c) The Author(s) 2021

\begin{abstract}
The impact of three different organosilicon compounds: poly(dimethylsiloxane) (PDMS), potassium methylsiliconate (MESI) and triethoxyoctylsilane (OTES), used as integral admixtures, on Portland cement hydration has been investigated by isothermal calorimetry and DTA-TG analysis. The silicon-based compounds are widely used as internal hydrophobic agents added into batch water; therefore, their effectiveness was investigated by means of capillary water absorption test. The isothermal calorimetry was used to measure the rate and amount of heat released during ordinary Portland cement hydration with integral organosilicon admixtures at $20^{\circ} \mathrm{C}, 30^{\circ} \mathrm{C}, 40{ }^{\circ} \mathrm{C}$ and $50{ }^{\circ} \mathrm{C}$. It allowed to determine the activation energy as well. The results indicate that used admixtures (except MESI admixture) decrease in the rate and amount of heat release during cement hydration. In addition, it is noticeable that the addition of MESI admixture significantly prolongs the induction period and delays hydration. In contrast to MESI and OTES admixtures, PDMS-based admixture does not affect significant on the activation energy. DTA-TG analysis had shown differences between reference sample and samples containing organosilicon admixtures during thermal decomposition, in terms of the amount of moisture and bound water, as well as $\mathrm{Ca}(\mathrm{OH})_{2} \mathrm{or}$ carbonates. The results presented in this paper enable a better understanding of the interactions between the organosilicon integral admixtures and the cement matrix. The study shows the effect of integral admixtures on cement hydration and thus the potential effect on the final properties of the cement-based material.
\end{abstract}

Keywords Portland cement hydration $\cdot$ Silane $\cdot$ Siloxane $\cdot$ Siliconate $\cdot$ Organosilicon admixture $\cdot$ Calorimetry

\section{Introduction}

The substantial development of concrete technology is mainly due to the application of chemical admixtures and mineral additives. The use of chemical additives is necessary to obtain structural concrete with high quality. Chemical admixtures used for concrete can be considered as one of the greatest achievements in civil engineering of the twentieth century. The first ideas for using concrete admixtures appeared at the beginning of the twentieth century. One of the first patents appeared in 1909 (the USA) and in 1911 (France). More work has been done in Great Britain in 1923, 1924 and 1925 [1]. The concrete admixtures market is still growing, and many types of them are currently available. According to the EN 934-2: 2002 standard [2], admixtures

Kalina Grabowska

kalina.grabowska@dokt.p.lodz.pl

1 Department of Building Materials Physics and Sustainable Design, Lodz University of Technology, Lodz, Poland are classified due to the effects of modifications. If a given admixture affects more than one property of a fresh or hardened concrete, it is treated as comprehensive (multifunctional) one. Mainly the EN 934-2:2002 standard [2] distinguishes the following types of admixtures: water reducers (plasticizers and superplasticizers), accelerators, set-retarders, aerators and permeability-reducing admixtures.

The main components of cement, i.e., calcium, silicates, aluminates and ferrite-aluminates, have a specific reactivity toward water. As a result of hydration process, the setting and hardening take place. Cement hydration is a long process (it may take several years [3]), which varies greatly with the cement type and blended mineral additives. After cement has been mixed with water adsorption of polar molecules of water on the surface of the cement grains occurs. This process precedes the dissolution or hydrolysis of the cement phases. Within a few minutes, a layer, almost entirely amorphous, forms. It is mainly composed of calcium sulfate and hydrated calcium silicates (C-S-H phases). When saturation is achieved, then supersaturation of the liquid phase 
with hydrolysis products takes place, and subsequently, rapid nucleation occurs. Subsequently, calcium hydroxide crystallizes and subsequent portions of hydrated calcium silicates are formed as rigid three-dimensional skeleton. The beginning of cement hydration is a heterogeneous process. It occurs at the interface between the solid phase (cement grain) and the liquid phase. This process depends on the specific surface area of the solid phase [3-5].

The hydration of the cement phases: alite $\left(\mathrm{C}_{3} \mathrm{~S}\right)$, belite $\left(\mathrm{C}_{2} \mathrm{~S}\right)$, calcium aluminate $\left(\mathrm{C}_{3} \mathrm{~A}\right)$ and calcium aluminoferrite $\left(\mathrm{C}_{4} \mathrm{AF}\right)$ is an exothermal reaction. The reaction between cement components and water within the initial hours is associated with the release of significant amounts of heat (approx. 250-400 $\mathrm{kJ} \mathrm{kg}^{-1}$ ) [6]. The hydration process accompanied by heat evolution has significant impact on durability of concrete massive structures. The total thermal effect depends on the hydration of individual cement components. The heat of hardening is determined by the heat of hydration of the dominant component of cements: alite (with hydration heat of about $500 \mathrm{~J} \mathrm{~g}^{-1}$ ) [6] and the heat of hydration of tricalcium aluminate. The content of $\mathrm{C}_{3} \mathrm{~A}$ does not exceed a dozen or so percent, but which, when hydrated, educe nearly $900 \mathrm{~J} \mathrm{~g}^{-1}$ [6]. The heat of hydration of belite and calcium aluminoferrite is about $250 \mathrm{~J} \mathrm{~g}^{-1}$ and $400 \mathrm{~J} \mathrm{~g}^{-1}$, respectively [6]. Reactions of calcium silicates with water, whose products are responsible for the increase in strength, have a dominant role in the hydration process. The aluminate and aluminoferrite phase mainly influences the initial bonding process and material durability, but their contribution to the increase in strength is unimportant [3, 5-7].

Admixtures can affect significantly the hydration of cement. As a result of using ones, hydration retardation is a consequence of precipitation of products or adsorption of particles from the solution on the surface of cement grains. There is a lot of papers describing influence of water reducers, accelerators, retardants and many different admixtures on cement hydration. But there is not enough research determining the impact of organosilicon, waterproofing admixtures on the hydration of Portland cement. Many researchers (see for example [1, 8-12]) made effort to understand and explain the Portland cement mechanism hydration in the presence of polymers. Polymer particles are mainly adsorbed on the surface of cement grains where the polymer cover is formed. It can inhibit the dissolution of mineral phases or it can hinder the nucleation of hydration products, such as C-S-H. It may retard the precipitation of hydration product (C-S-H) by decrease in $\mathrm{Ca}^{2+}$ ion concentration in the pore solution and thus extend the time required to get the necessary supersaturation $[9$, 13]. Łukowski [14] and Kubens [13] listed three possible mechanisms of polymer-cement reactions: (1) the electrostatic interaction between the polymer and the surface of cement grains, (2) steric hindrance of adsorbed polymer to another particle of polymer adsorbed on adjacent cement grain and (3) hydrophilic mechanism in case of admixtures based on surfactants.

There are many physical and chemical corrosive phenomena, i.e., cyclic freezing, carbonation, chloride corrosion, which shorten the service life of cement-based materials. Most of them are triggered or proceed in the presence of water filling the concrete pores. In order to extend the durability of concrete, one should keep it dry or with low water content. There are a few ways to achieve this goal, one of which is to use the hydrophobic admixtures. Organosilicon agents are usually applied as the external coating. The other way is to add the hydrophobic admixture to the concrete mixture as one of the ingredients. Consequently, the understanding how these hydrophobic, organosilicon compounds influence the cement hydration becomes a critical issue. Organosilicon compounds are very popular in building construction industry. They have plenty of application as, e.g., protective coating and sealing materials. Due to their properties, organosilicon compounds are often used in building industry as protection against moisture. In response to the needs of producers of building materials, attempts are made to use organosilicon compounds as volume hydrophobization agents. It is the purpose of this paper to investigate the impact of three different silicon-based water-repellents on Portland cement hydration and better understanding of the interaction mechanisms involved. The hydrophobic admixtures are aimed to be added in a mixing water as we intend to produce the internal hydrophobic material. Three, commercially available, chemical admixtures recommended by the producers for internal hydrophobization are described below. Comprehensive research of cement materials with hydrophobic admixtures such as isothermal calorimetry and thermal analysis: Differential thermal analyse (DTA) and thermogravimetric (TG) are important to determine the influence and dominant reaction mechanism of organosilicon admixtures. An isothermal calorimetric and DTATG analysis was executed on cement pastes with three different silicon-based water-repellents. To confirm the volume hydrophobic properties, capillary water absorption tests were performed on cement mortar.

In case of organosilicon agents used as admixtures available scientific literature shows miscellaneous influence of silicon-based water-repellents on the characteristics of cementitious materials. It should be remembered that the results published in this paper cannot be directly compared with the results of the other authors. It is caused by, for example, differences in the types and forms (emulsions, powders, etc.) of the tested organosilicon compounds, the dosing method, used amount or other components of admixtures such as surfactants, stabilizers, solvents, etc. 


\section{Materials}

A characteristic feature of organosilicon compounds is a stable bond between silicon and carbon, nitrogen or sulfur. Most of them have similar properties as ordinary organic compounds: They are colorless, hydrophobic and stable. The silicon atom, in most organosilicon compounds, is tetravalent. The length of carbon-silicon bond is $186 \mathrm{pm}$ and is longer than carbon-carbon bond $(154 \mathrm{pm})$. It is also weaker (the dissociation energy of the bond is $451 \mathrm{~kJ} \mathrm{~mol}^{-1}$ ) than carbon-carbon one $\left(607 \mathrm{~kJ} \mathrm{~mol}^{-1}\right)$, which makes atoms separation easier [15]. The higher electronegativity of carbon causes polarization of $\mathrm{C}-\mathrm{Si}$ bond toward carbon. Silicon is less electronegative (1.8) than carbon (2.5). The result is an ionic character of the silicon-oxygen bond. Si-O-Si named as siloxane bonds, and $\mathrm{Si}-\mathrm{C}-\mathrm{Si}$ referred as silicon carbon bonds are the basic structures of organosilicon polymers. The polysiloxane chain, built with silicon and oxygen atoms (-O-Si-O-Si-O-), is the fundamental structure of organosilicon compounds. The angle between silicon and oxygen in siloxane chain is rather large (about $120^{\circ}$ [15]) and changeable. Due to that, the chain is very flexible $[15,16]$. The structure of polysiloxanes is described by a repeating group: $-\left[\mathrm{R}_{2} \mathrm{Si}-\mathrm{O}\right]-$. Organosilicon compounds are commonly known and referred as "silicones." They are synthetic organosilicon polymers with siloxane chains in which silicon atoms are attached to alkyl (most often methyl or ethyl) or aryl (most often phenyl) groups. Organic group is attached to one atom of silicon only along the polysiloxane chain. The structure of substituents affects the variety of spatial systems that can be formed from basic chains [15-17]. One of the most popular of organosilicon polymers is poly(dimethylsiloxane). PDMS is a high-molecular polymer with two methyl groups $\left(-\mathrm{CH}_{3}\right)$ attached to silicon atom (Fig. 1a). As a result of small size of methyl group, the poly(dimethylsiloxane) chains can be arranged in helix, with methyl groups directed outward. These organic substituents are responsible for hydrophobic properties. Inorganic chain with strongly polar $\mathrm{Si}-\mathrm{O}$ bonds ( $\mathrm{Si}-\mathrm{O}$ bonds have ionic character in 50\%) and non-polar organic groups attached to silicon atom gives polysiloxanes amphiphilic character, affecting their properties. Siloxane chains, due to their amphiphilicity, can easily take on a conformation corresponding to the minimum-free energy of the surface [18-20]. Size of alkyl substituent affects the hydrophobic properties of polysiloxanes. Longer chain of organic group causes higher water-repellency. But in practice, larger substituents than propyl are not applied due to impact on the other properties of organosilicon polymers [15]. Poly(dimethylsiloxane) is the main component of one of used admixtures.

Another one is based on potassium methylsiliconate (MESI) (Fig. 1b). Until now, potassium and sodium siliconates have been used for surface hydrophobization. MESI is
Fig. 1 Schematic structure of: (a) poly(dimethylsiloxane) (b) potassium methylsiliconate (c) triethoxyoctylsilane $(\mathbf{d})$ silicone resin<smiles>C[Si](C)(C)O[Si](C)(C)C</smiles>

(b)<smiles>C[Si](O)(O)O</smiles>

(c)<smiles>CCCCC[Si](OCC)(OCC)OCC</smiles>

(d)

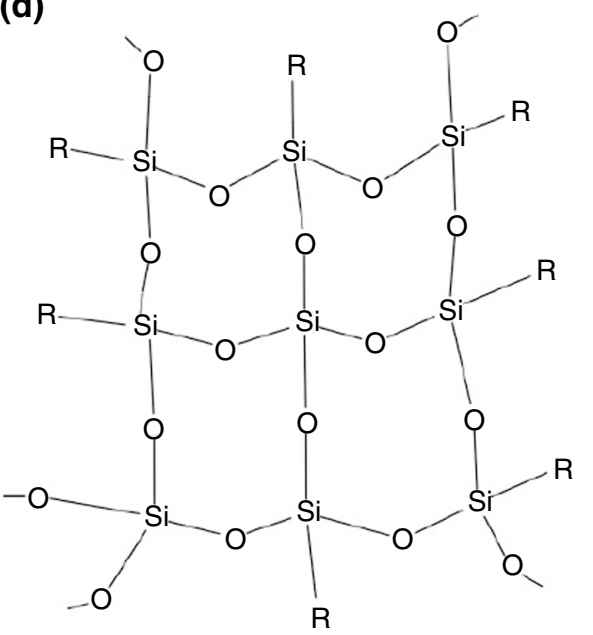


an alkaline solution of oligomeric siloxanes, namely methylsiloxane resin (Fig. 1d). Siliconates are formed as a result of stopping the polycondensation reaction of resin by adding excess of sodium or potassium hydroxide. Siliconates decompose under the $\mathrm{CO}_{2}$ contained in the air and moisture presence. Subsequently, because of polymerization reaction, a polysiloxane chain and corresponding carbonate are formed. During the polymerization reaction, longer polysiloxane chains are formed, and the hydrophobic effect can be observed. It should be mentioned that while carbon dioxide accelerates polymerization, calcium hydroxide delays it $[15,20-22]$. The mechanism of polycondensation reaction of MESI due to carbonization is shown in Fig. 2 [23, 24].

The main component of the last admixture is triethoxyoctylsilane (OTES) (Fig. 1c). It belongs to a group of organosilicon compounds called silanes. They are low molecular mass (178), monomeric molecules based on one atom of silicon with four substituents. The general formula of silane is: $\mathrm{R}_{\mathrm{n}} \mathrm{SiX}_{4-\mathrm{n}}$. In silane derivatives, there are two types of substituents which can be attached to the main atom. A "R" means a moiety such as hydrogen atom, an alkyl, aryl, aromatic or organofunctional group (or their combination). The presence of alkyl groups provides a hydrophobic properties. Mostly, they are aliphatic chains such as isobutyl or octyl. A " $\mathrm{X}$ " moiety can be a halogen atom or an alkoxy (mostly methoxy or ethoxy) group which is needed to form covalent bonds with inorganic substrate. Due to the presence of alkoxy groups and ongoing reactions, methanol or ethanol is formed as a byproduct. These alkoxy groups can ensure the linkage with inorganic cement matrix [8, 16, 25, 26]. Triethoxyoctylsilane is an alkyl alkoxy silane with three ethoxy groups and one octyl group in its structure (Fig. 1c). The hydrolysis and polycondensation reaction are shown in Fig. 3. The hydrolysis reactions of silane take place in alkaline medium and with the presence of water. These two conditions are met in environment of cement matrix. Alkoxy groups react with water molecules with detached an alcohol and form silanols group $(\mathrm{Si}-\mathrm{OH})$. Subsequently, due to hydroxyl groups $(-\mathrm{OH})$, condensation reaction of silane takes place, and the water is eliminated. Free, residual hydroxyl groups interact with mineral, hydrophilic substrate of cement grain (with available hydroxyl groups at the hydrophilic surface to be specific). It leads to covalent bonds formation between organosilicon compound and cement substrate, and polysiloxane chain is also forming. Silane is absorbed on hydrophilic surface with water elimination [10, 26, 27]. The schematic reaction is shown in Fig. 4. The characterization of the used organosilicon admixtures is given in Table 1 .

The ordinary Portland cement CEM I 42.5 R was used for all studied cement pastes and mortars. The chemical composition of cement is given in Table 2 [28]. The water-cement ratio of cement pastes and mortars was constant, and it was equal to 0.5 . Four main types of cement pastes or mortars were prepared: reference sample and three different samples with three different commercial admixtures based on various organosilicon compounds. The cement pastes were prepared for thermal analysis (DTA-TG) and isothermal calorimetry test. The cement mortars were prepared for capillary water absorption test. Table 3 shows the composition of prepared cement mortars.

Three different hydrophobic admixtures with three various active silicon compounds were used. The first admixture includes reactive polysiloxanes applied as a water emulsion. Poly(dimethylsiloxane) is the main component. The second water-repellent is based on triethoxyoctylsilane, and the third admixture is concentrated, water solution of methyl silicon resin. Amount of added hydrophobic admixture per cement mass was $1 \%, 2 \%$ or $3 \%$. For third admixture (MESI), the
Fig. 2 Schematic mechanism of potassium methylsiliconate reactions (" $R$ " is a methyl ($\mathrm{CH}_{3}$ ) group and "Me" may be sodium or potassium atom)<smiles>[R][Si](O)(OC)O[C@H](O)[C@@H](O)O[Si]([R])(O)OC</smiles>

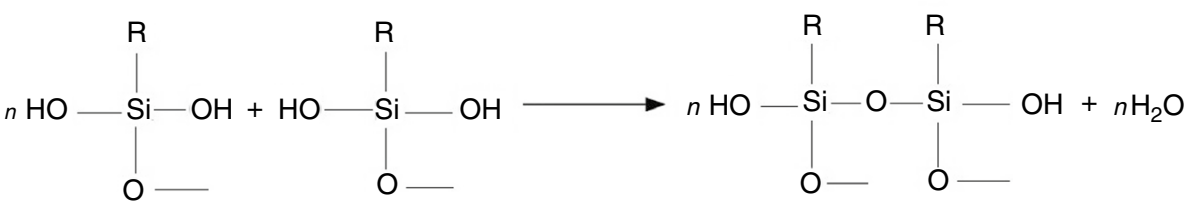

Fig. 3 Schematic mechanism of hydrolysis and polycondensation of alkyl ethoxysilane, where " $\mathrm{R}$ " is an alkyl group (such as octyl)

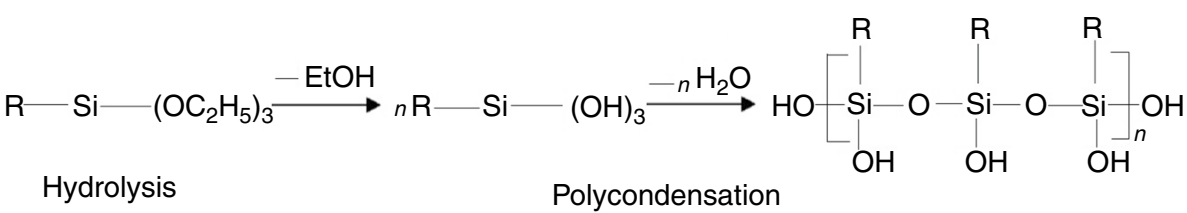




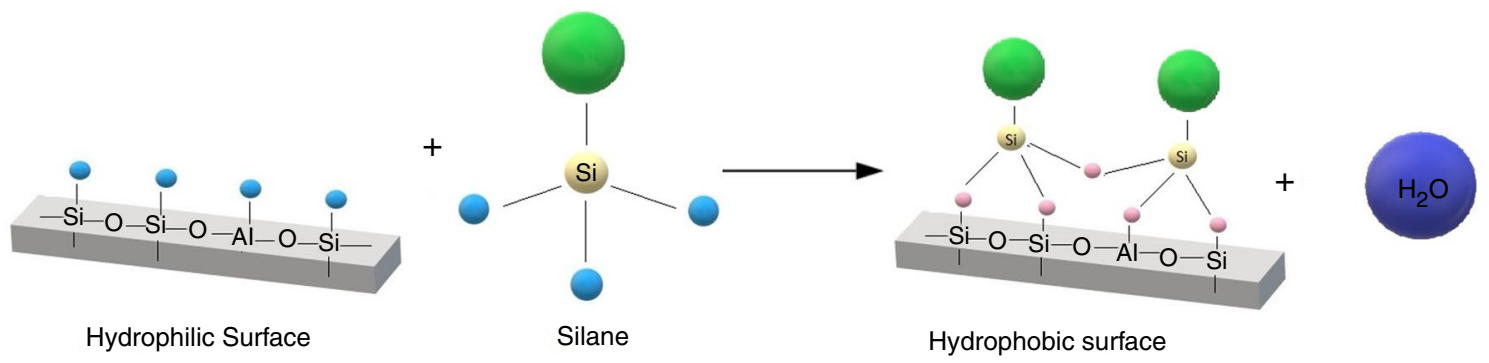

OH groups $\bigcirc \mathrm{O}$ atoms $\bigcirc$ Octyl groups $\left(-\mathrm{C}_{8} \mathrm{H}_{17}\right)$

Fig. 4 Schematic reaction of silane with hydrophilic substrate leading to hydrophobic one

Table 1 Description of the water-repellent admixtures

Table 2 Chemical composition of Portland cement CEM I [28]

producer recommends diminishing the batch water by $10 \%$ in the mix. Authors decided that the sum of batch water and MESI-based admixture should equal $225 \mathrm{~g}$ to keep w/c ratio at the constant level.

\begin{tabular}{ll}
\hline Chemical composition/\%mass \\
\hline Ignition loss & 2.8 \\
Insoluble residue & 0.46 \\
$\mathrm{SO}_{3}$ & 2.76 \\
$\mathrm{Chloride}$ content $\left(\mathrm{Cl}^{-}\right)$ & 0.066 \\
$\mathrm{Na}_{2} \mathrm{O}$ & 0.18 \\
$\mathrm{MgO}$ & 1.45 \\
$\mathrm{CaO}$ & 63.89 \\
$\mathrm{SiO}$ & 19.96 \\
$\mathrm{Al}_{2} \mathrm{O}_{3}$ & 5.21 \\
$\mathrm{Fe}_{2} \mathrm{O}_{3}$ & 2.68 \\
$\mathrm{CaO}_{2}$ free & 1.87 \\
\hline
\end{tabular}

\begin{tabular}{lllll}
\hline & Admixture & Main agent & Active content/\% & Type of solvent \\
\hline 1 & PDMS & Poly(dimethylsiloxane) & $\sim 70$ & Water \\
2 & OTES & Triethoxyoctylsilane & $\sim 45-50$ & \\
3 & MESI & Solution of methyl silicone resin & $\sim 40$ & \\
\hline
\end{tabular}

\section{Methods}

\section{Capillary water absorption tests}

In capillary water absorption test, the mortar prismatic samples, with dimension $80 \times 40 \times 40 \mathrm{~mm}$, were used. After 28 days of curing mortar, samples were dried at $80{ }^{\circ} \mathrm{C}$. Subsequently, four sides of each specimen were covered by sealing material. Samples were vertically putted in water to a depth of $1 \mathrm{~cm}$ and weighed after $10 \mathrm{~min}, 30 \mathrm{~min}, 60 \mathrm{~min}$, $90 \mathrm{~min}, 2 \mathrm{~h}, 3 \mathrm{~h}, 4 \mathrm{~h}$ and $24 \mathrm{~h}$. Test was carried out according to EN 1015-18 [29].

\section{Isothermal calorimetric measurements}

The heat of hydration of cement paste with hydrophobic admixtures was determined with an isothermal heat conduction calorimeter (TAM Air) according to the EN 196-11:2019-01 [30]. The calorimetric study was performed at temperature
Table 3 Cement mortar composition

\begin{tabular}{|c|c|c|c|c|c|c|c|c|c|}
\hline \multirow{3}{*}{$\begin{array}{l}\text { Component } \\
\text { Amount of admixture/\% }\end{array}$} & \multicolumn{9}{|c|}{ Admixture } \\
\hline & \multicolumn{3}{|c|}{ PDMS } & \multicolumn{3}{|c|}{ OTES } & \multicolumn{3}{|l|}{ MESI } \\
\hline & 1 & 2 & 3 & 1 & 2 & 3 & 1 & 2 & 3 \\
\hline Water/cement ratio & 0.5 & & & & & & & & \\
\hline Cement/g & 450 & & & & & & & & \\
\hline Sand/g & 1350 & & & & & & & & \\
\hline Water/g & 225 & & & 225 & & & 220.5 & 216.0 & 211.5 \\
\hline Hydrophobic admixture/g & 4.5 & 9.0 & 13.5 & 4.5 & 9.0 & 13.5 & 4.5 & 9.0 & 13.5 \\
\hline
\end{tabular}


of $20^{\circ} \mathrm{C}, 30{ }^{\circ} \mathrm{C}, 40{ }^{\circ} \mathrm{C}$ and $50{ }^{\circ} \mathrm{C}$ for the cement pastes made of Portland cement CEM I 42.5 R with addition of $1,2 \%$ or $3 \%$ of each organosilicon (PDMS, OTES, MESI) admixture and with the water-cement ratio of 0.5 . A cement paste without any admixture was also included as the reference sample. For each type of cement paste, two samples were prepared. Cement, water and appropriate admixture were manually blended together outside the calorimeter and because of that the first hydration peak could not be recorded. Only the second peak could be registered. The time of investigation was set as 7 days. In accordance with EN 196-11 standard, the measurement of heat of hydration of cement should last up to 7 days in order to receive correspondence between isothermal calorimetry and EN 196-8: Methods of testing cement-Part 8: Heat of hydration-Solution method and EN 196-9: Methods of testing cement—Part 9: Heat of hydration-Semi-adiabatic method. There is no doubt that cement hydration does not stop after 7 days. However, no significant heat sources are observed in calorimetric studies [31]. After 7 days, the progress of the hydration can be measured by compressive strength, XRD, etc. Calorimetric measurements at four different $\left(20^{\circ} \mathrm{C}, 30^{\circ} \mathrm{C}\right.$, $40^{\circ} \mathrm{C}$ and $50^{\circ} \mathrm{C}$ ) temperatures allowed to, by determining the degree of hydration and its rate evolutions along with time, specify the activation energies of hydration process for the cement pastes with silicon-based integral water-repellents. Hydration activation energy of cement pastes can be determined by using Arrhenius law [32]:

$K(T)=A \exp -\left(\frac{E_{\mathrm{a}}}{\mathrm{RT}}\right)$

where $K(T)$ is the rate constant at the temperature $T, A$ is the proportionality factor, $E_{\mathrm{a}}$ is the activation energy, and $R$ is the universal gas constant $\left(8.314 \mathrm{~J} \mathrm{~mol}^{-1} \mathrm{~K}^{-1}\right)$. The methodology provided by Ulm and Coussy [33, 34], Cervera et al. [35], Gawin et al. [36] and Bazant et al. [37] allowed describe the hydration degree $\Gamma_{\text {hydr }}$ as heat released during hydration:

$\Gamma_{\text {hydr }}(t)=\frac{Q_{\text {hydr }}(t)}{Q_{\text {hydr } \infty}}$

where $Q_{\text {hydr }}(t)$ is amount of heat released during cement hydration, and $Q_{h y d r \infty}$ is the total amount of released heat. According to the EN 196-11:2019-01 [30], it was assumed that the total amount of released heat $Q_{\text {hydro }}$ equals to the value measured after 7 days of hydration $Q_{\text {hydr,7 days. }}$ The progress of cement hydration process can be expressed as:

$\frac{\mathrm{d} \Gamma_{\mathrm{hydr}}}{\mathrm{d} t}=\bar{A}_{\Gamma}\left(\Gamma_{\mathrm{hydr}}\right) \beta_{\mathrm{RH}} \exp -\left(\frac{E_{\mathrm{a}}}{\mathrm{RT}}\right)$

where $\overline{\mathrm{A}}_{\Gamma}\left(\Gamma_{\text {hydr }}\right)$ is a normalized chemical affinity related to the hydration degree, and $\beta_{\mathrm{RH}}$ is an empirical coefficient related to influence of relative humidity on the hydration rate. The isothermal measurements, based on the amount of heat released by the sample, allowed to determine the hydration degree (Eq. 2) and its evolution in time (Eq. 3). Consequently, the activation energy $\left.E_{\mathrm{a}}\right|_{\Gamma_{\text {hydr }}}$ for arbitrary hydration degrees can be determined by following relation:

$\left.E_{\mathrm{a}}\right|_{\Gamma_{\text {hydr }}}=R\left(\frac{1}{T_{0}}-\frac{1}{T}\right)^{-1}\left[\left.\ln \frac{\mathrm{d} \Gamma_{\text {hydr }}}{\mathrm{d} t}\right|_{\Gamma_{\text {hydr }, T}}-\left.\ln \frac{\mathrm{d} \Gamma_{\text {hydr }}}{\mathrm{d} t}\right|_{\Gamma_{\text {hydr }, \mathrm{T}_{0}}}\right]$

\section{Thermal analysis DTA-TG}

The thermal analysis was performed only for the cement pastes made of Portland cement CEM I $42.5 \mathrm{R}$ with 3\% addition of each admixture (PDMS, OTES, MESI). Water to cement ratio was 0.5 . The age of the tested cement pastes samples was 90 days. The differential thermal analyse and thermogravimetric (DTA-TG) measurements were performed using the SETSYS 16/18 thermal analyser. The measurements were executed at the temperature range 20-800 ${ }^{\circ} \mathrm{C}$, applying the temperature rate equal $5^{\circ} \mathrm{C} \mathrm{min}^{-1}$. The sample mass was approximately $10-20 \mathrm{mg}$. The carrier gas was a synthetic air, and the volumetric flow rate of the carrier gas was $40 \mathrm{~cm}^{3} \mathrm{~min}^{-1}$. Prior to each measurement, samples were degassed for purification.

\section{Results and discussion}

\section{Capillary water absorption tests}

Table 4 and Fig. 5 summarize the results of capillary water absorption test. Each value is taken over six prismatic samples $(80 \times 40 \times 40 \mathrm{~mm})$. Both, silane- and siloxane-based admixtures gave noticeable decrease in water absorption caused by capillary suction. The addition of poly(dimethylsiloxane) (PDMS) affects significantly the water absorption. Addition of PDMS admixture reduced referred absorption coefficient approximately by half. The best hydrophobic effect showed admixture based on triethoxyoctylsilane. Addition of 3\% of OTES reduced absorption coefficient up to $90 \%$. Najduchowska et al. [38], Spaeth et al. [12] and Milenković et al. [39] achieved similar results. Spaeth et al. [12] mentioned that silane powder gave better results than the other tested admixtures. As we can see the presence of organic groups (such as methyl, octyl, etc.) provides hydrophobic properties to modified materials. Addition of methylsiliconate (MESI) did not decrease water absorption at all. Capillary water absorption coefficient was even higher than reference one. 
Table 4 Results of capillary water absorption test of hydrophobized cement mortar

\begin{tabular}{lll}
\hline Water-repellent agent & $\begin{array}{l}\text { Amount of } \\
\text { admixture/\% }\end{array}$ & $\begin{array}{l}\text { Capillary water absorption } \\
\text { coefficient } / \mathrm{kg} \mathrm{m}^{-2} \mathrm{~min}^{-0.5}\end{array}$ \\
\hline Reference & 0 & 0.210 \\
PDMS & 1 & 0.115 \\
& 2 & 0.106 \\
OTES & 3 & 0.098 \\
& 1 & 0.042 \\
MESI & 2 & 0.023 \\
& 3 & 0.020 \\
& 1 & 0.248 \\
& 2 & 0.259 \\
\hline
\end{tabular}

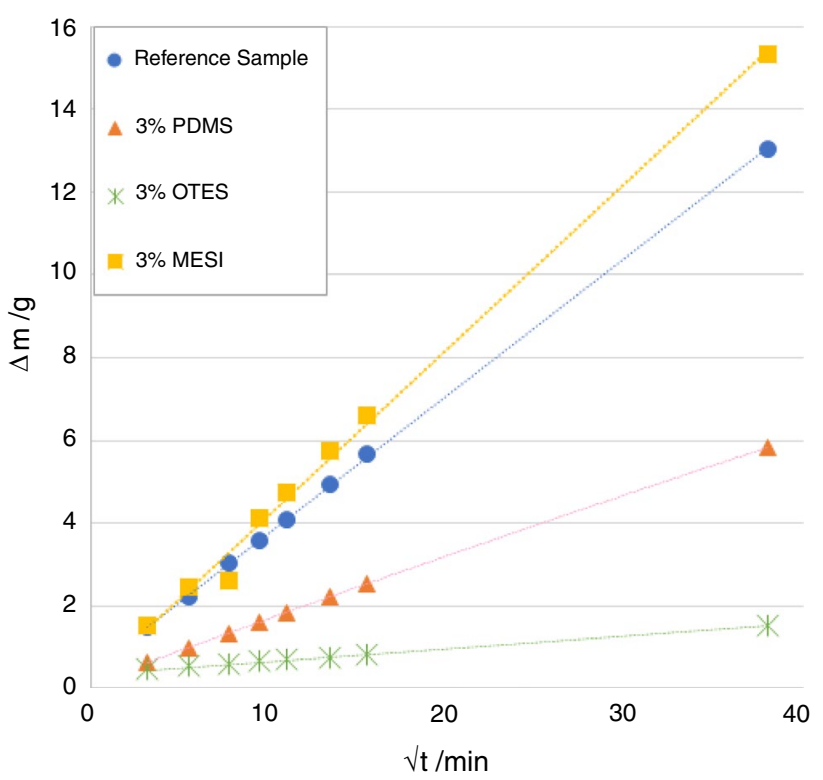

Fig. 5 Mass changes of cement mortar samples during capillary water absorption test

Obtained results indicate that the longer alkyl chain of octyl groups provided greater decrease in capillary water absorption than the methyl one. In addition, the silane undergoes a polycondensation reaction during cement hydration unlike polysiloxane compound, which perhaps, led to better formed and developed siloxane chain and hence better protection against water. In case of MESI admixture, there is no hydrophobic effect observed. It might be explained by the fact that the siliconates need $\mathrm{CO}_{2}$ for polycondensation to form a siloxane chain. Adding methylsiliconate as integral admixture caused a hinder in access to $\mathrm{CO}_{2}$ from air, which prevented the polymerization reaction.

\section{Isothermal calorimetric measurements}

The hydration process and related heat production can be presented by data obtained during the measurement of the rate of heat released under isothermal conditions. Isothermal calorimetry is a helpful and effective method to observe the exothermal reactions during cement hydration and determine the impact of individual components on it. Due to device limitations, the first peak of cement hydration, associated with the hydration of the aluminate $\left(\mathrm{C}_{3} \mathrm{~A}\right)$ phases, is not registered. The main observed peak refers to alite hydration [40]. Impact of water-repellents on the rate of heat release in cement pastes during hydration is shown in Fig. 6a, b and c. As can be easily seen, each of used admixtures has noticeable influence in the amount of heat generated during cement hydration. In addition, MESI admixture, as only one, significant extended the induction period and delayed the main hydration peak. The retardation of cement hydration in MESI pastes is probably due to the steric effect provided by aqueous solution of silicon resin. After $41 \mathrm{~h}$ of cement hydration, the total amount of released heat (relative to the cement mass) is lower for samples with organosilicon admixtures (Table 5). After 7 days of cement hydration, the total amount of released heat (relative to the cement mass) is also decreased except 3\% MESI sample (Table 5). All three silicon-based agents decreased in amount of released heat during cement hydration. The reduction in the amount of heat generated during hydration directly indicates the interaction of organosilicon compounds with the cement phases. By adsorbing on the cement grains surface hydrophobic admixtures led to hinder reaction with water and thus to incomplete or delayed cement hydration. Similar conclusions were reached by the Stoch at el. [41] by using FT-IR, XRD, DTA and SEM techniques. They studied the reactions of poly(dimethylsiloxane) with pure clinker phases such as alite, belite and the tricalcium aluminate phase. They found out that polysiloxane admixture affects both the quality and quantity of cement hydration products. Among others, they showed that PDMS reduced amount of calcium hydroxide formed during alite and belite hydration, and at the same time, increased in carbonates formation. In case of OTES admixture, during the cement hydration process, silane molecules hydrolyze to silanols ( $\mathrm{RO}-\mathrm{S}-\mathrm{OH})$. The reactive alkoxy groups (-OR) provide the polycondensation reaction with form a siloxane bond (-Si-O-Si-). Due to the presence of hydroxyl groups $(-\mathrm{OH})$ reaction with the clinker cement phases occur. Alkyl chains (such as octyl $-\mathrm{C}_{8} \mathrm{H}_{17}$ groups) in addition to the hydrophobic effect also ensure steric protection to the alkoxy groups. It provides sustained linkage of siloxane chains with cement matrix in an alkaline environment of pore solution. It also needs to be remembered that the alkaline environment (high value of $\mathrm{pH}$ ) of hydrated cement increases the hydrolysis rate [39, 42]. Apparently 

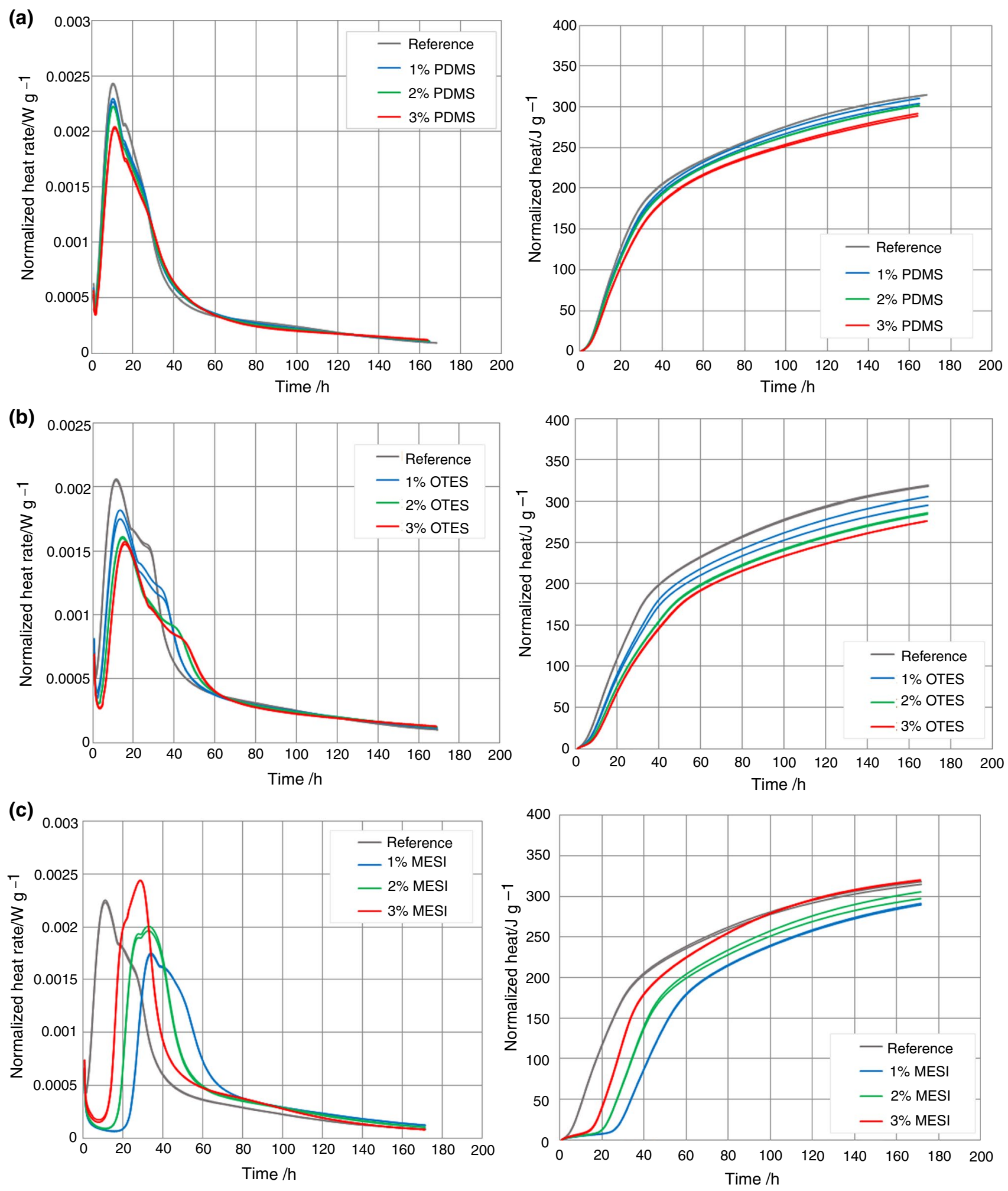

Fig. 6 Influence of (a) PDMS (b) OTES (c) MESI admixture on heat rate and normalized heat of hydration as a function of time at $20{ }^{\circ} \mathrm{C}$

(Fig. 6b and Table 5), the hydrolysis and polycondensation reactions of triethoxyoctylsilane affected more on cement hydration than simply interaction between PDMS molecules and cement phases. The amount of heat after $41 \mathrm{~h}$ or 7 days is evidently lower than for polysiloxane admixture. As always in the case of using a commercially available admixture, we 
Table 5 Influence of organosilicon admixtures on heat of hydration in $20^{\circ} \mathrm{C}$

\begin{tabular}{llll}
\hline Water-repellent agent & $\begin{array}{l}\text { Amount of admix- } \\
\text { ture/\% }\end{array}$ & $\begin{array}{l}\text { Average heat of hydration } \\
\text { after } 41 \mathrm{~h} / \mathrm{J} \mathrm{g}^{-1}\end{array}$ & $\begin{array}{l}\text { Average heat of hydra- } \\
\text { tion after } 7 \text { days/ } \mathrm{g} \mathrm{g}^{-1}\end{array}$ \\
\hline Reference & 0 & 206.75 & 314.69 \\
PDMS & 1 & 199.04 & 307.28 \\
& 2 & 194.85 & 301.61 \\
OTES & 3 & 185.09 & 290.24 \\
& 1 & 180.04 & 300.30 \\
MESI & 2 & 157.78 & 285.16 \\
& 3 & 149.12 & 276.09 \\
& 1 & 93.60 & 290.59 \\
& 2 & 144.93 & 301.37 \\
\hline
\end{tabular}

know nothing about solvent, surfactants, emulsifiers, etc., which are used during production process and which can affect the cement hydration and thus on properties of material. However, knowing the condensation scheme of silanes (Fig. 3), we know that alcohol molecules (in our case ethanol) are detached. Kong et al. [43] examined the effect of methanol and ethanol on cement hydration. They confirmed that alcohols slightly reduce the main peak of cement hydration without retardation, which should be taken into consideration. Feng et al. [11] also noticed a retarding effect of silanes (amino, vinyl and epoxy-based) on cement hydration and heat development. All organosilicon-based admixtures used in [11] delayed cement hydration significantly and decreased in heat generated during hydration. Feng et al. also considered that retarding effect of silanes is associated with the adsorption of silanes on cement grains and hydration products [11]. Also, Casagrande et al. [44] and Kong et al. [43], who studied polycarboxylate-ester-based superplasticizers partial substituted by silanes, noticed cement hydration retardation. A similar observation has Collodetti et al. [45], who studied influence of surface modified (by silanes) nano- $\mathrm{SiO}_{2}$ on Portland cement hydration. Moreover, cumulative heat flow was lower for samples with modified nano- $\mathrm{SiO}_{2}$ than reference sample.

Results of the isothermal calorimetric tests carried out for the cement pastes with organosilicon admixtures (with dosage of $3 \%$ of each) at $20^{\circ} \mathrm{C}, 30{ }^{\circ} \mathrm{C}, 40{ }^{\circ} \mathrm{C}$ and $50{ }^{\circ} \mathrm{C}$ are presented in Figs. 7a-d. It allowed to determine the effect of temperature on the cement hydration in the presence of silicon-based admixtures. Admixture based on potassium siliconate caused two noticeable effects: retardation of cement hydration and increasing in the amount of released heat at $20{ }^{\circ} \mathrm{C}, 30{ }^{\circ} \mathrm{C}, 40{ }^{\circ} \mathrm{C}$. At $50{ }^{\circ} \mathrm{C}$ (Fig. 7d), a slight delay of hydration is observed but reference sample released more heat. At each temperature, silane admixture led to a slight hydration retardation with significant decreased in the amount of released heat. PDMS curves have the greatest similarity to the reference one. However, a decreased in the amount of released heat is noticeable at $20{ }^{\circ} \mathrm{C}, 40{ }^{\circ} \mathrm{C}$ and $50{ }^{\circ} \mathrm{C}$. Interestingly, at $30^{\circ} \mathrm{C}$, poly(dimethylsiloxane) caused a greater heat release before the end of the first $10 \mathrm{~h}$ of measurement. By measurements carried out at different temperatures, it was possible to determine the activation energy of cement, which was calculated based on the methodology provided by Ulm and Coussy [33, 34], Cervera et al. [35], Gawin et al. [36] and Bazant et al. [37]. In Fig. 8a-d, the hydration activation energy is shown as the results of the activation energy $E_{a}$ divided by the gas constant $R$ (which is equal to $8.314 \mathrm{~J} \mathrm{~mol}^{-1} \mathrm{~K}^{-1}$ ). There is some research (see for e.g. [46-48]) which determines the activation energy of cement hydration by means of calorimetric test. In the [46, 47] papers, the researchers obtained a quite similar activation energy $E_{\mathrm{a}}$ for ordinary Portland cement. Schmid et al. [48], using the rearranged Ulm and Coussy's rate law, observed that the activation energy increases along with the growth of cement hydration degree. As the authors [48] pointed out during Portland cement hydration, a few, different reactions of cement phases occur (e.g., dissolution of $\mathrm{C}_{3} \mathrm{~S}$, dissolution and participation of $\mathrm{CSH}$ and $\mathrm{Ca}(\mathrm{OH})_{2}$, dissolution of $\mathrm{C}_{3} \mathrm{~A}$, etc.) which may alternate the activation energy. Much research indicates that despite the use of the same type of cement (CEM I 42.5), the obtained calorimetric results may vary significantly. The results are sensitive to factors such as: the manufacturing company, production batch or way of storage. However, the results in [48] are very interesting and this matter should be investigated in more detailed. As might be seen in Fig. 8a-d, the value of activation energy depends on both temperature and hydration degree. Let us focus on the change of activation energy $\left(E_{\mathrm{a}} / R\right)$ as a function of hydration degree. In range of $0.3-0.5$, in case of potassium siliconate, the highest activation energy (9303 K) was achieved at $30{ }^{\circ} \mathrm{C}$. It was the highest recorded value. The cement paste with OTES stood out the highest activation energy at $40{ }^{\circ} \mathrm{C}$ when reference sample or with PDMS had the highest activation energy at $50{ }^{\circ} \mathrm{C}$. In range of $0.55-0.8$ of hydration degree, a steady decreased in activation energy 
(a)
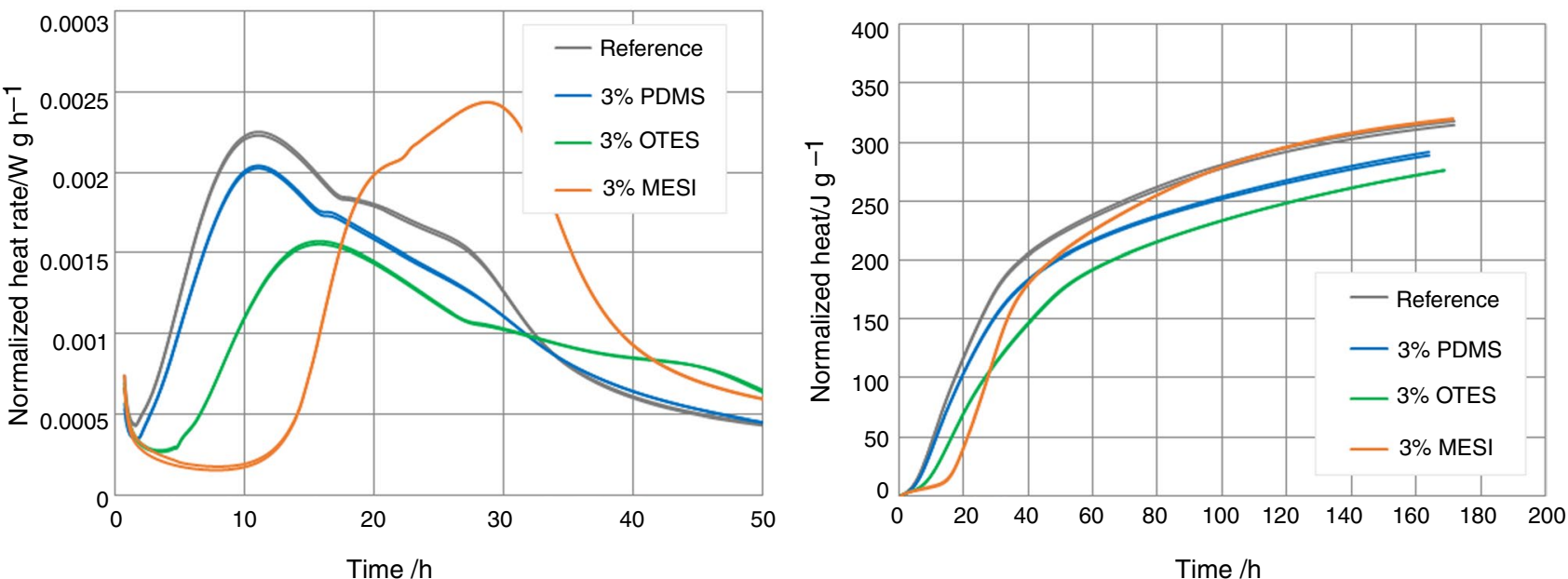

(b)
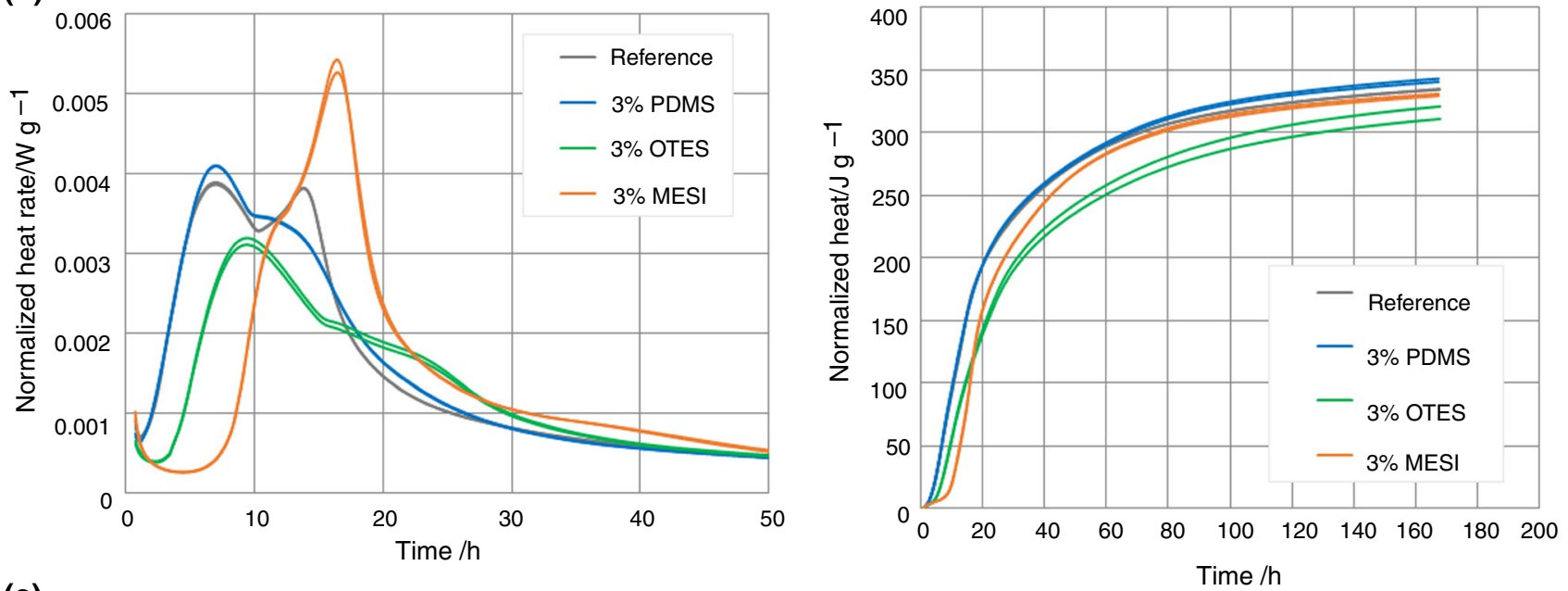

(c)
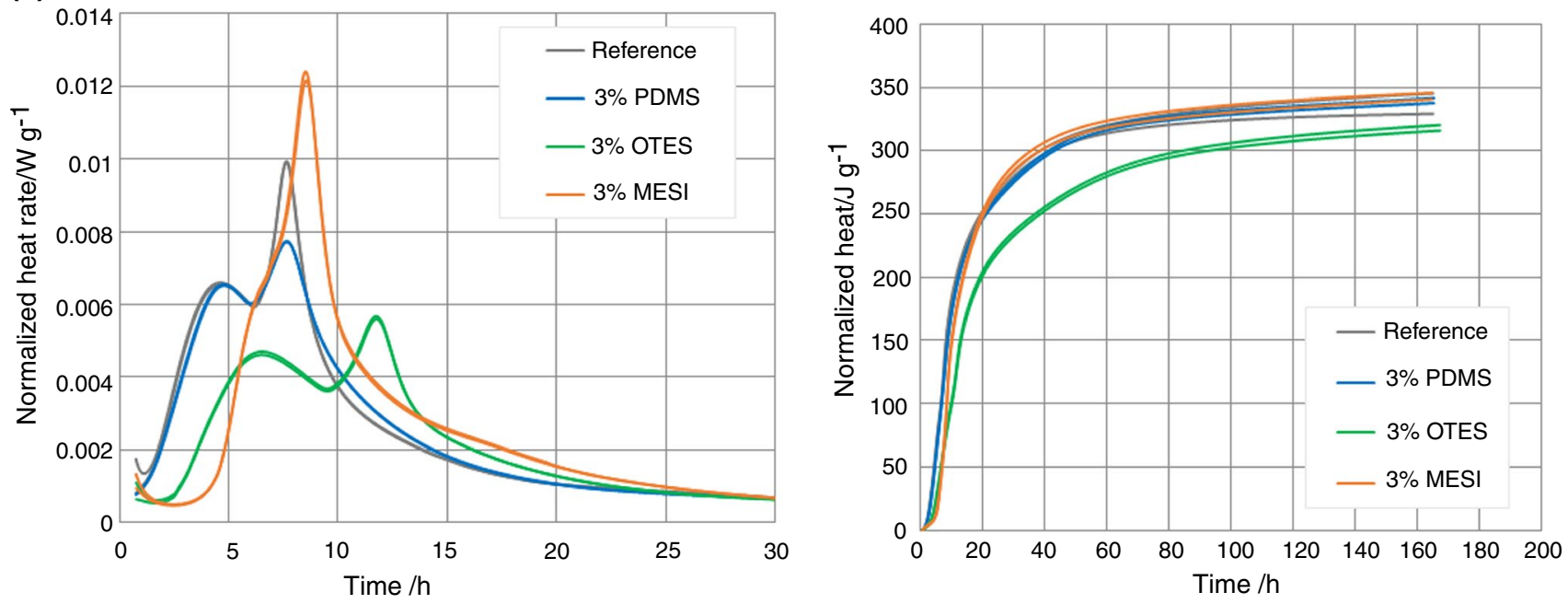

Fig. 7 Heat rate and normalized heat of hydration as a function of time, obtained from the calorimetric tests performed at (a) $20{ }^{\circ} \mathrm{C}(\mathbf{b}) 30{ }^{\circ} \mathrm{C}$, (c) $40{ }^{\circ} \mathrm{C}$ and (d) $50{ }^{\circ} \mathrm{C}$ for cement pastes 

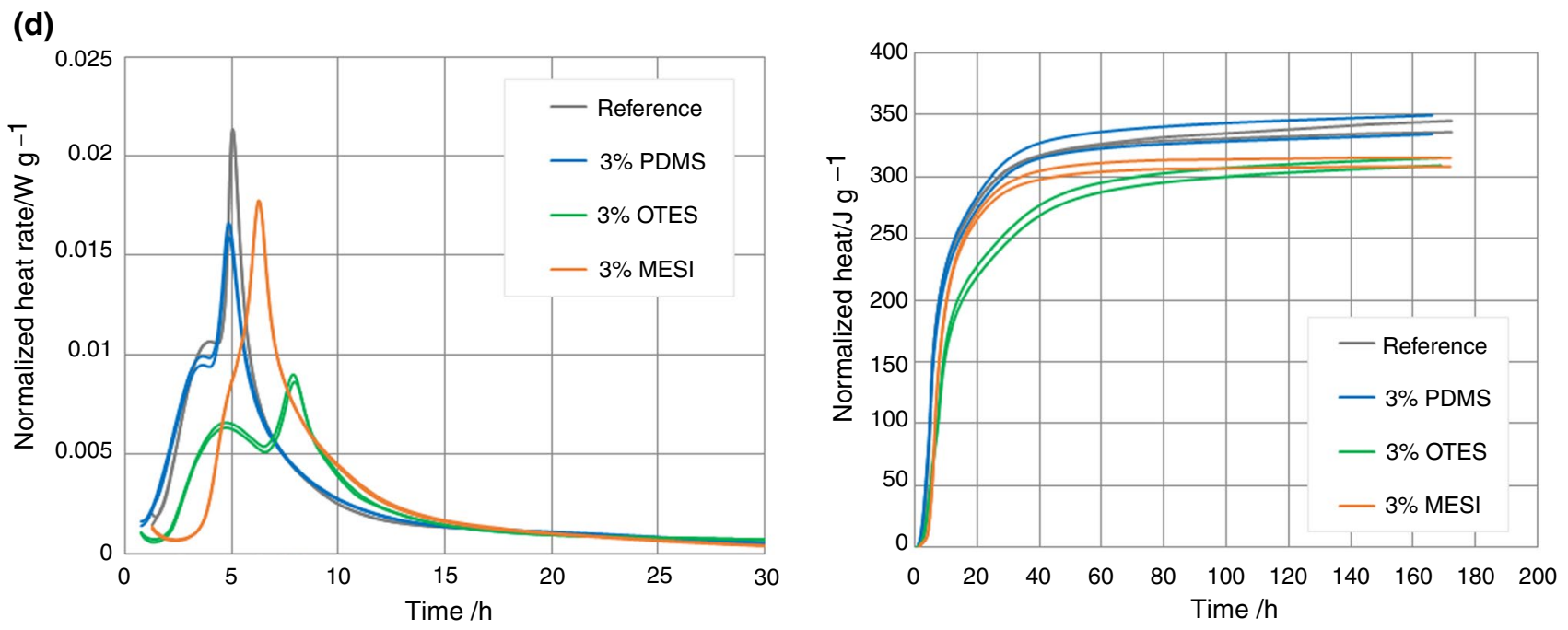

Fig. 7 (continued)

(a)

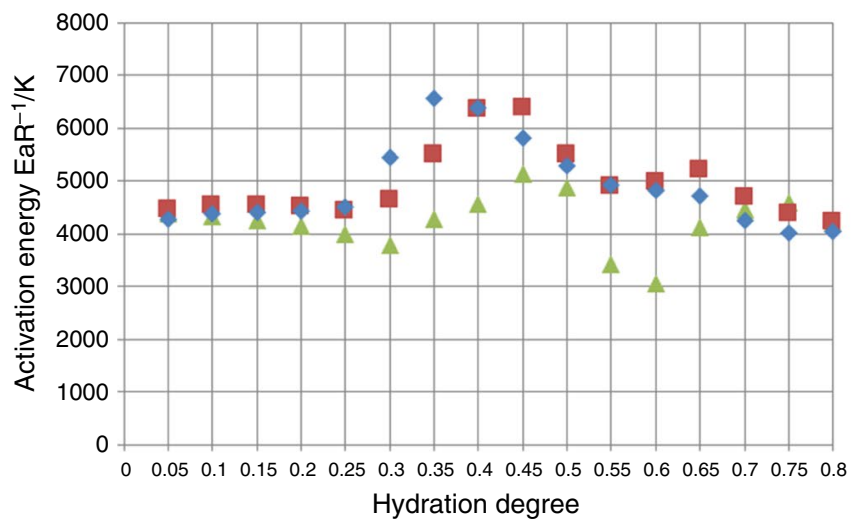

(c)

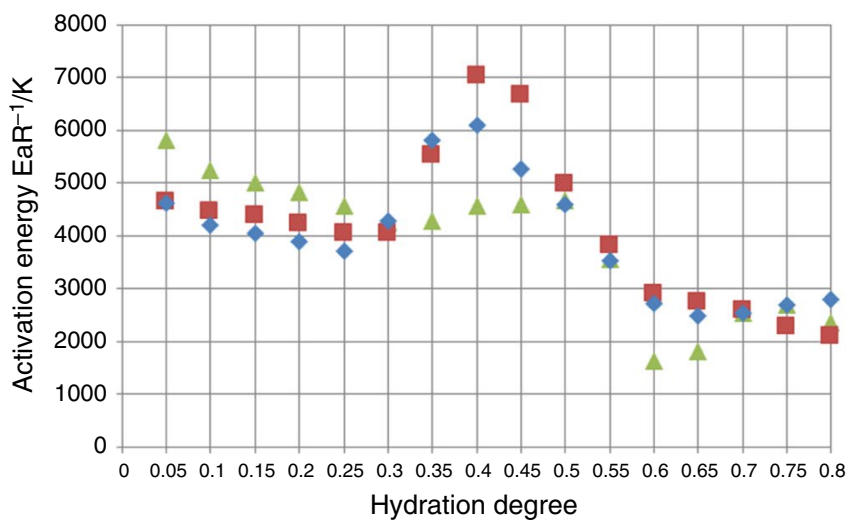

(b)

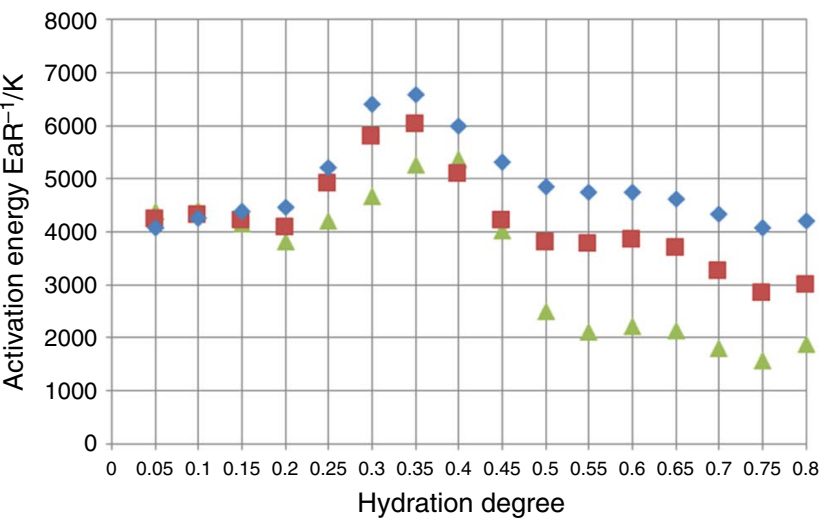

(d)

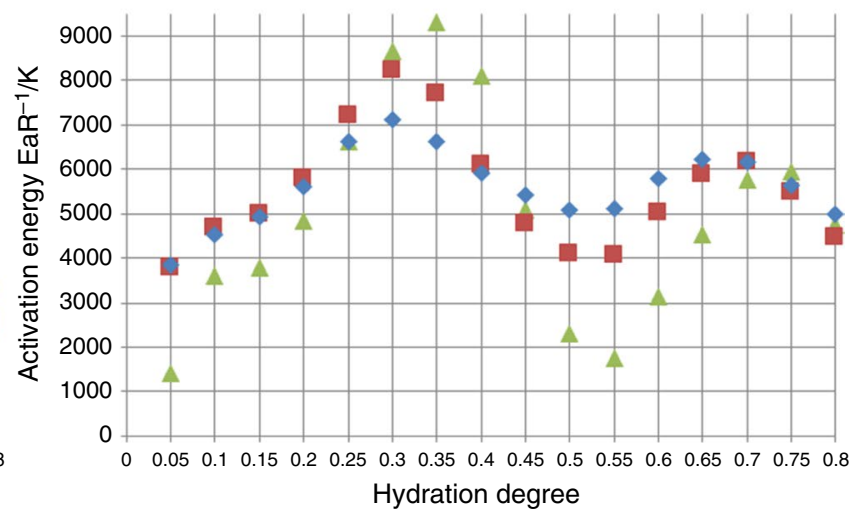

Fig. 8 Activation energy $\left(E_{d} / R\right)$ as a function of hydration degree of cement pastes with (a) no admixture (b) 3\% PDMS (c) 3\% OTES and (d) 3\% MESI admixture

was observed for all cement pastes except MESI admixture. Approximately $0.65-0.7$ of hydration degree a small peak was observed. Cement paste with potassium methyl siliconate, unlike the other samples, was characterized by two peaks during the study of activation energy and also its largest and smallest value. In the range of $0.05-0.25$ of 
hydration degree curves of reference and PDMS sample have the most similar shape calculated for all analysed temperatures, contrary to MESI specimens where it was the lowest.

\section{DTA-TG analysis}

All DTA-TG curves presented in Fig. 9 show similar shape. DTA-TG analysis of cement pastes shows the several distinctive endothermic effects (Fig. 1b) accompanied by mass loss (Fig. 1a). The endothermic peaks occurring in range of $100-200{ }^{\circ} \mathrm{C}$ are associated with: a) removal of the free water present in the pore system and physically adsorbed one to the surface $\left(100-140{ }^{\circ} \mathrm{C}\right)$ [49-52] and (b) in range of $160-180^{\circ} \mathrm{C}$, removal of the chemically bound, interlayer water from the hydrates (dehydration of the calcium silicate hydrates (CSH) gel) [50-53]. According to the scientific literature [50-53], the dehydration process of calcium silicate hydrates might occur even up to temperature $300{ }^{\circ} \mathrm{C}$. The endothermic minimum observed in the temperature range of $390-470{ }^{\circ} \mathrm{C}$ is assigned to the dehydration of portlandite $\mathrm{Ca}(\mathrm{OH})_{2}$ [49-53]. The endothermic effect at $700{ }^{\circ} \mathrm{C}$ is associated with the decomposition of carbonates [51, 52]. Analysing the DTG curves (Fig. 9a) and comparing to the total mass loss (Table 6) of the samples, it can be stated that their masses' loss is quite similar. The largest mass loss $(21.27 \%)$ was observed for the sample containing of $3 \%$ of MESI admixture. The lowest one was obtained for 3\% addition of OTES (18.18\%). The mass loss of reference sample was $21.32 \%$, and sample with PDMS was $20.82 \%$. As can be seen in Fig. 9a and Table 6, the MESI sample contained the highest amount of free water (13.96\%). Almost the same amount of physisorbed water had PDMS sample (13.54\%). In both cases, it is by $2 \%$ more than reference sample.
Table 6 Mass changes during thermal analysis DTA-TG

\begin{tabular}{llr}
\hline Admixture & Temperature $/{ }^{\circ} \mathrm{C}$ & Mass loss $/ \%$ \\
\hline $0 \%$ & $100-140$ & 11.67 \\
& $160-180$ & 3.87 \\
& $\sim 450$ & 4.69 \\
& $\sim 700$ & 1.09 \\
Total mass loss & & 21.32 \\
PDMS (3\%) & $100-140$ & 13.54 \\
& $160-180$ & 2.64 \\
& $\sim 450$ & 3.46 \\
Total mass loss & $\sim 700$ & 1.18 \\
OTES (3\%) & & 20.82 \\
& $100-140$ & 9.38 \\
Total mass loss & $160-180$ & 3.68 \\
MESI (3\%) & $\sim 450$ & 3.99 \\
& $\sim 700$ & 1.13 \\
Total mass loss & $100-140$ & 18.18 \\
\hline
\end{tabular}

Probably it is relating to the structure of the organosilicon compounds. Both poly(dimethylsiloxane) and aqueous solution of methyl silicon resin (MESI) have complex, extensive particles (see Fig. 1a for PDMS and Fig. 1d for MESI). Their size might hinder the water-cement reactions and absorption of water molecules on the cement phases. The lowest value of mass loss was obtained for OTES paste (9.38\%). In the case of the second, much smaller endothermic peak (a)

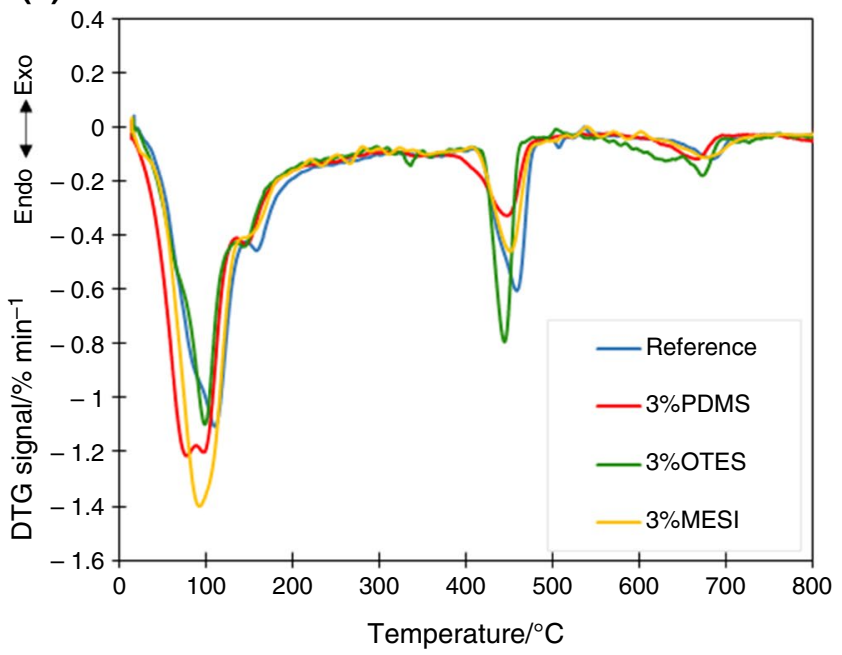

(b)

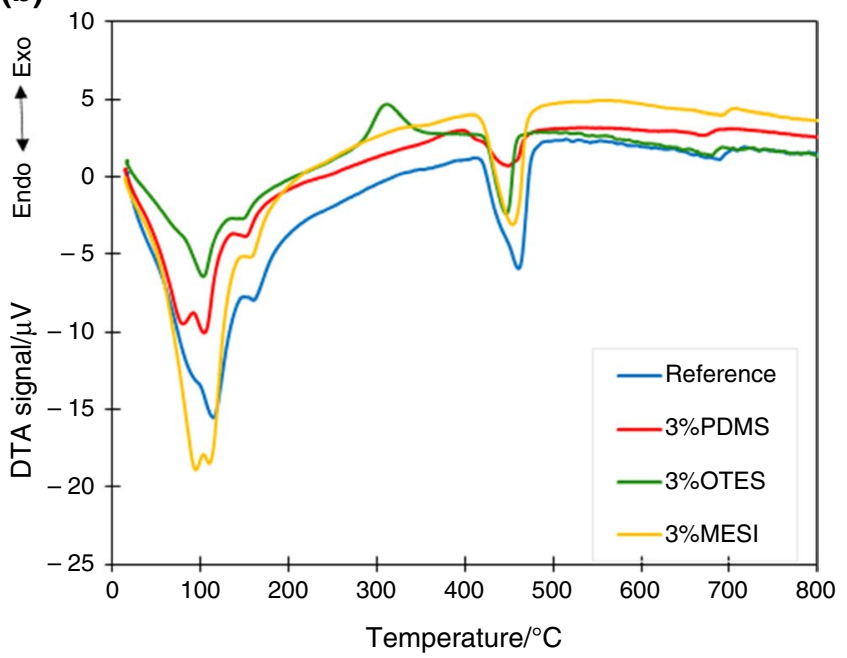

Fig. 9 (a) DTG (b) DTA curves of cement pastes 
$\left(160-180{ }^{\circ} \mathrm{C}\right)$, assigned to the chemically bounded water, almost the same mass loss was observed for reference sample $(3.87 \%)$ and OTES (3.68\%). The other two admixtures (PDMS and MESI) had similar mass loss (2.64\% and $2.41 \%$, respectively). The third endothermic peak at the temperature about $450{ }^{\circ} \mathrm{C}$ corresponds to the decomposition of calcium hydroxide $\left(\mathrm{Ca}(\mathrm{OH})_{2}\right)$. The highest amount of $\mathrm{Ca}(\mathrm{OH})_{2}$ was formed in reference sample (4.69\%) and the lowest one in PDMS and MESI samples (3.46\% and 3.47\%, respectively). For OTES sample, it was $3.99 \%$, but at the same time, the rate of mass loss for this sample was the fastest. DTA/DTG curves indicated slight mass loss (about $1 \%$ ) at $\sim 700{ }^{\circ} \mathrm{C}$, which reflects the decomposition of calcium carbonate [30]. The highest mass loss was obtained for MESI sample $(1.43 \%)$ which can be caused by formed carbonates during siliconate reactions (scheme in Fig. 2). In case of 3\% OTES sample, a small exothermic effect (Fig. 9b) around $310{ }^{\circ} \mathrm{C}$ occurs. Since we do not know the full composition of the triethoxyoctylsilane-based admixture, we cannot explain this phenomenon with absolute certainty. However, the literature $[51,54]$ provides two credible explanation. It can be assumed that the exothermic effect is associated with the decomposition of organic compounds such as polymer. The DTA-TG analyse confirmed that organosilicon compounds interact with cement during hydration making water binding or forming portlandite $\left(\mathrm{Ca}(\mathrm{OH})_{2}\right)$ difficult.

\section{Conclusions}

The influence of three different organosilicon compounds, namely the poly(dimethylsiloxane), the triethoxyoctylsilane and the solution of potassium methyl siliconate, on the Portland cement hydration and capillary water absorption of cement mortar was determined. Based on the obtained results and the discussion presented above, the following conclusions can be drawn.

- The use of organosilicon admixtures caused a decrease in heat released during cement hydration. The difference depends on the type of silicon-based compound. The greatest impact on the delays of cement hydration showed the MESI-based admixture. The lowest value of hydration heat of cement paste for MESI $\left(93.60 \mathrm{~J} \mathrm{~g}^{-1}\right)$ might imply the better steric effect of resin structure (MESI) than the other ones (siloxane chains in PDMS or OTES). As the temperature of measurement increased, the OTES-based admixture caused the largest decreased in the release heat.

- Result of DTA-TG analysis showed that all organosilicon admixtures interfere the portlandite $\left(\mathrm{Ca}(\mathrm{OH})_{2}\right)$ formation, which indicate the reactions of organosilicon compounds with cement phases during cement hydration.
- Capillary water absorption test shows the great potential for using polysiloxanes and silanes as water-repellents for internal hydrophobization of cementitious materials.

- In case of potassium methyl siliconate, it turned out that the small dosage might act like set-retarder.

Preliminary studies have shown that organosilicon admixtures are not neutral to minerals phases of cement and interact with them during hydration. It affects the hydration reactions and the properties of the final product. The use of organosilicon admixtures as potential hydrophobic agent can be very promising solution for cement-based materials. However, it requires further research to thoroughly understand the mechanism of interaction of silicon-based compounds with cement in order to eliminate the negative effects of their use and the possibility of giving the desired properties to cementitious materials.

Authors' contribution All authors contributed to the study conception and design. Material preparation, data collection and analysis were performed by Kalina Grabowska and Marcin Koniorczyk. The first draft of the manuscript was written by Kalina Grabowska and Marcin Koniorczyk. Both authors revised, read and approved the final manuscript.

Funding No funding was received to assist with the preparation of this manuscript.

Data availability Authors made sure that all data and materials support their published claims and comply with field standards.

\section{Declarations}

Conflict of interest The authors have no conflict of interests to disclose.

Open Access This article is licensed under a Creative Commons Attribution 4.0 International License, which permits use, sharing, adaptation, distribution and reproduction in any medium or format, as long as you give appropriate credit to the original author(s) and the source, provide a link to the Creative Commons licence, and indicate if changes were made. The images or other third party material in this article are included in the article's Creative Commons licence, unless indicated otherwise in a credit line to the material. If material is not included in the article's Creative Commons licence and your intended use is not permitted by statutory regulation or exceeds the permitted use, you will need to obtain permission directly from the copyright holder. To view a copy of this licence, visit http://creativecommons.org/licenses/by/4.0/.

\section{References}

1. Chandra S, Flodin P. Interactions of polymers and organic admixtures on Portland cement hydration. Cem Concr Res. 1987; 17:875-90.

2. EN 934-2:2009 Admixtures for concrete, mortar and grout - Part 2: concrete admixtures - definitions, requirements, conformity, 
marking and labelling. Brussels: European Committee for Standardization; 2009.

3. Kurdowski W. Cement and concrete chemistry. PWN: Polish Cement Publishing House; 2010.

4. Nocun-Wczelik W. Impact of selected concrete additives on the speed of cement hydrating. XII Scientific and technical symposium: cement - properties and application Gliwice. 2010; 79-90.

5. Neville A.M. Properties of concrete. 5th ed. Longman; 2012.

6. Nocun-Wczelik W. Effect of mineral admixtures on the heat of cement hydration. V scientific and technical symposium rheology in concrete technology, Gliwice. 2003; 47-58.

7. Gruyaert E, Robeyst N, De Belie N. Study of the hydration of Portland cement blended with blast-furnace slag by calorimetry and thermogravimetry. J Therm Anal Calorim. 2010;102:941-51.

8. Suessmuth J, Gerdes A. Computational chemistry to investigate the chemical behavior of silanes and $\mathrm{CSH}-\mathrm{Gel}$. 5th international conference on water repellent treatment of building materials hydrophobe V, Aedificatio Publishers. 2008; 233-244.

9. Lu Z, Kong X, Zhang C, Cai Y. Effect of highly carboxylated colloidal polymers on cement hydration and interactions with calcium ions. Cem Concr Res. 2018;113:140-53.

10. Lecomte J-P, Thibaut M, Stammer A. Encapsulated silicone/ silane mix enhances water resistance of mortars. Eur Coat J. 2007;12:46-51.

11. Feng H, Le HTN, Zhang WS, M-H. . Effects of silanes and silane derivatives on cement hydration and mechanical properties of mortars. Constr Build Mater. 2016;129:48-60.

12. Spaeth V, Lecomte J-P, Delplancke M-P, Orlowsky J, Büttner T. Impact of silane and siloxane based hydrophobic powder on cement-based mortar. Adv Mat Res. 2013;687:100-6.

13. Kubens S. Interaction of cement and admixtures and its effect on rheological properties. Gottingen: Cuvillier Verlag; 2010.

14. Łukowski P. Concrete modification (in Polish). Cracow: Polish Cement Publishing House; 2016.

15. Barnat-Hunek D. Surface free energy as a factor affecting hydrophobisation effectiveness in protection of building construction; (in Polish). Lublin, Poland: Publishing House Lublin University of Technology; 2016.

16. Liu Y. Silicon dispersion. CRC Press: Routledge; 2017.

17. Bielański A. Foundations in Inorganic Chemistry (in Polish). T. 2. Scientific Publisher PWN, Warsaw; 2002.

18. Mojsiewicz-Pieńkowska K, Łukasiak J. Polydimethylsiloxanes in human environment. Polymers. 2003;48:403-9.

19. Chruściel J, Leśniak E, Fejdyś M. Carbofunctional silanes and polysiloxanes. Part II. Preparation and applications of carbofunctional polysiloxanes. Polymers. 2008;53:817-29.

20. Grabowska K, Koniorczyk M. The effect of hydrophobic treatment by organosilicon admixtures of cement mortar. Cem Wapno Beton. 2019;4:320-9.

21. Szymura T. Chemistry of engineering materials (in Polish). Lublin, Poland: Publishing House Lublin University of Technology; 2015.

22. Ciabach J. Properties of synthetic resins used in monument conservation (in Polish). Nicolaus Copernicus University Publishing House; 2001.

23. Fleury M, Branlard $\mathrm{P}$, Lenormand R, Zarcone C. Intermediate wettability by chemical treatment. J Petrol Sci Eng. 1999;24:123-30.

24. Rościszewski P, Zielecka M. Silicones - properties and applications (in Polish). Warsaw: Scientific and Technical Publishers; 2002.

25. Roos, M, König, F, Stadtmüller S. and Weyershausen B. Evolution of silicone based water repellents for modern building protection. 5th International conference on water repellent treatment of building materials hydrophobe V, Aedificatio Publishers. 2008; 3-16.

26. Witucki GL. A Silane primer: chemistry and applications of alkoxy silanes. J Coat Technol Res. 1993;65:57-60.
27. Moriconi G, Tittarelli F, Corinaldesi V. Review of silicone-based hydrophobic treatment and admixtures for concrete. Indian Concr J. 2002;76:637-42.

28. Wieczorek A, Bednarska D, Koniorczyk M. Characterization of pore structure for permeability prediction of cement based materials under frost attack - The fractal approach. Thermophysics 2018. AIP Conference Proceedings. 2018; 1988:020005

29. EN 1015-18:2002 Methods of test for mortar for masonry - Part 18: determination of water absorption coefficient due to capillary action of hardened mortar. Brussels: European Committee for Standardization; 2002.

30. EN 196-11:2019-01 Methods of testing cement - Part 11: Heat of hydration - isothermal conduction calorimetry method. Brussels: European committee for standardization; 2019.

31. Linderoth O, Wadso L, Jansen D. Long-term cement hydration studies with isothermal calorimetry. Cem Concr Res. 2021;141:106344.

32. Kada-Benameur H, Wirquin E, Duthoit B. Determination of apparent activation energy of concrete by isothermal calorimetry. Cem Concr Res. 2000;30:301-5.

33. Ulm F-J, Coussy O. Modeling of thermo-chemo-mechanical couplings of concrete at early ages. J Eng Mech. 1995;121:785-94.

34. Ulm F-J, Coussy O. Strength growth as chemo-plastic hardening in early age concrete. J Eng Mech. 1996;122:1123-32.

35. Cervera M, Olivier J, Prato T. Thermo-chemo-mechanical model for concrete. I: hydration and aging. J Eng Mech ASCE. 1999;125:1018-27.

36. Gawin D, Pesavento F, Schrefler BA. Hygro-thermo-chemomechanical modelling of concrete at early ages and beyond. Part I: hydration and hygro-thermal phenomena. Int J Numer Meth Eng. 2006;67:299-331.

37. Bazant ZP, Najjar LJ. Nonlinear water diffusion in nonsaturated concrete. Mater Struct. 1972;5:3-20.

38. Najduchowska M, Pichniarczyk P. Effect of hydrophobic agents on the properties of cement and gypsum mortars. Cem Wapno Beton. 2010;3:141-8.

39. Milenković N, Staquet S, Lecomte J-P, Pierre C, Delplancke M-P. Non-ionic silane emulsion as integral water repellent impact on cement hydration process. 7 th international conference on water repellent treatment of building materials hydrophobe VII, LNEC. 2014; 47-56.

40. Scrivener KL, Nonat A. Hydration of cementitious materials, present and future. Cem Concr Res. 2011;41:651-65.

41. Stoch A, Zdaniewicz M, Cz P. The effect of polymethylsiloxanes on hydration of clinker phases. J Mol Struct. 1999;511-512:319-25.

42. Arkles B, Steinmetz JR, Zazyczny J, Mehta P. Factors contributing to the stability of alkoxysilanes in aqueous solution. $\mathbf{J}$ ADHES SCI TECHNOL. 1992;6:193-206.

43. Kong X-M, Liua H, Lu Z-B, Wang D-M. The influence of silanes on hydration and strength development of cementitious systems. Cem Concr Res. 2015;67:168-78.

44. Casagrande CA, Jochem LF, Onghero L, de Matos PR, Repette WL, Gleize PJP. Effect of partial substitution of superplasticizer by silanes in Portland cement pastes. J Build Eng. 2020;29:101226.

45. Collodeti G, Gleize PJP, Monteiro PJM. Exploring the potential of siloxane surface modified nano-SiO2 to improve the Portland cement pastes hydration properties. Constr Build Mater. 2014;54:99-105.

46. D'Aloia L, Chanvillard G. Determining the "“apparent" activation energy of concrete Ea-numerical simulations of the heat of hydration of cement. Cem Concr Res. 2002;32:1277-89. 
47. Poole JL, Riding KA, Folliard KJ, Juenger MCG, Schindler AK. Methods for calculating activation energy for Portland cement. ACI Mater J. 2007;104(1):303-11.

48. Schmid M, Pichler Ch, Lackner R. Engineering hydration model for ordinary Portland cement based on heat flow calorimetry data. J Therm Anal Calorim. 2019;138:2283-8.

49. Panea I, Hansenb W. Investigation of blended cement hydration by isothermal calorimetry and thermal analysis. Cem Concr Res. 2014;35:1155-64.

50. Stepkowska ET, Perez-Rodriguez JL, Jimenez de Haro MC, Sayagues MJ. Study of hydration of two cements of different strengths. J Therm Anal Calorim. 2002;69:187-204.

51. Stepkowska ET, Blanes JM, Real C, Perez-Rodriguez JL. Hydration products in two aged cement pastes. J Therm Anal Calorim. 2005;82:731-9.

52. Lazau I, Pacurariu C, Ciobanu C. The use of thermal analysis to investigate the effects of cellulose ethers on the Portland cement hydration. J Therm Anal Calorim. 2012;110:103-10.
53. Petkova V, Stoyanov V, Pelovski Y. TG-DTG-DTA in studying white self-compacting cement mortars. J Therm Anal Calorim. 2012;109:797-806.

54. Kh Al-Noaimi K, El-Hosiny FI, Abo-El-nein SA. Thermal and pore structural characteristics of polymer-impregnated and superplasticized cement pastes. J Therm Anal Calorim. 2000;61:173-80.

Publisher's Note Springer Nature remains neutral with regard to jurisdictional claims in published maps and institutional affiliations. 